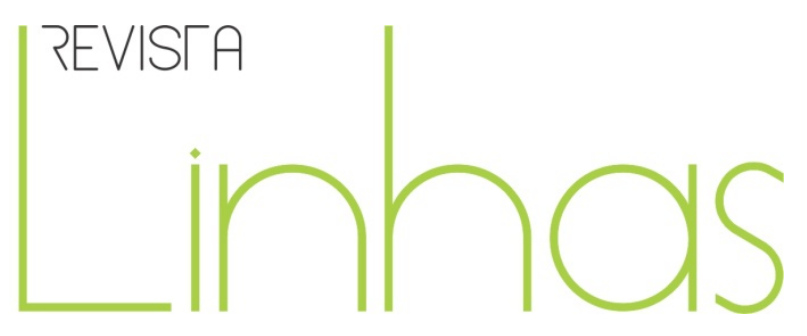

\title{
Imagens de infância: uma possível historiografia da infância
}

\section{Resumo}

As imagens de infância são testemunhos mudos, mas vivos, que atestam a presença da criança em diferentes situações, "brincando no seu limiar", analisadas através de vetores múltiplos, mas unificados, que retiram as imagens de seu fluxo natural e, através de montagens possibilitadas pela inserção na sociedade da qual ela faz parte, possíveis pela iconografia em diferentes organizações sociais, anulam fronteiras: como o brincar, este gesto infantil sério e necessário, que quebra o contínuo e cria o seu próprio mundo. São como sinais de infância que formam labirintos, caminhos possíveis de recuperação do passado para construir o presente, demarcados pelo significado de infância como a particularidade de um sentimento que expressa a graça, a beleza e a diferença do mundo infantil. O objetivo deste artigo, em que insistimos na beleza da infância, é apostar na possibilidade de que todas as crianças, homens e mulheres de nosso tempo tenham garantido o seu direito à infância como um patrimônio da humanidade; para tanto, destacamos uma imagem de beleza e possível vida digna para todo ser humano, independente de classe social, nacionalidade, etnia e diversidade cultural.

Palavras-chave: Cultura infantil. Imagens de infância. Sentimento de infância. História da criança. Pedagogia da beleza da infância.
Telma Anita Piacentini Doutora em Educação pela USP, com estágio na Università degli Studi di Ferrara/Itália. Professora e pesquisadora aposentada da Universidade Federal de Santa Catarina - UFSC telma.anita@gmail.com

\section{Para citar este artigo:}

PIACENTINI, Telma Anita. Imagens de infância: uma possível historiografia da infância. Revista Linhas, Florianópolis, v. 14, n. 26, jan./jun. 2013. p. 157 - 170.

\section{DOI: $10.5965 / 1984723814262013157$}

http://dx.doi.org/10.5965/1984723814262013157 


\title{
Images of childhood: a possible historiography of childhood
}

\begin{abstract}
Images of childhood are silent but living witnesses that attest to the presence of the child in different situations, "playing at their limen". The images are analyzed through multiple, but unified vectors that remove them from their natural flow and, through assemblages made possible by insertion in the society of which they are a part, by the iconography in different social organizations, they annul frontiers. They also play, this serious and necessary childish gesture that breaks the continuum and creates their own world. They are like signs of childhood that form labyrinths, possible routes for the recovery of our past to construct the present, marked by the meaning of childhood as the particularity of a feeling that expresses the grace, beauty and difference of the childhood world. The purpose of this article, in which we insist on the beauty of childhood, is to invest in the possibility that all children, men and women of our time have a guaranteed right to childhood as a human patrimony. To do so, we highlight an image of beauty and the possibility of a decent life for all human beings, regardless of social class, nationality, ethnicity and cultural diversity.
\end{abstract}

Keywords: Childhood culture. Images of childhood. Semiotics of childhood. History of childhood. Pedagogy of the beauty of childhood 
Uma das artimanhas do capitalismo é fragmentar as situações para disfarçar a razão. Logo, é necessário ter a consciência de que aqui existe criança que passa fome, que não brinca, não estuda (ou recebe uma educação precária), sofre abusos sexuais, é explorada, abandonada, discriminada, espancada, e não tem garantidos todos os direitos estabelecidos pelo ECA - Estatuto da Criança e do Adolescente.

(Fernanda Regina, desacato. inf/2012/11)

Abrir as portas do mundo infantil e trilhar labirintos percorridos em diferentes tempos exige determinadas condutas. Mesmo para se permitir ousadias, estas condutas precisam cercar-se de procedimentos científico-metodológicos, que garantam um mínimo de coerência e um máximo de observações que o universo selecionado caracteriza e indica. O universo referido é o mundo da criança, o especificamente infantil, numa amplitude cujo limite está cercado pelo que o distingue: basicamente o mundo adulto. $\mathrm{E}$, mais ainda, este mundo infantil está caracterizado por um significado de infância, enquanto conceito universal, expresso pelo fio condutor de um sentimento de infância.

O sentimento de infância a que nos referimos não está circunscrito às idades da vida, nem a uma periodização fixada pelos ciclos da natureza ou da organização da sociedade, que poderia ser sintetizada, grosso modo, em infância, juventude e velhice. Não se liga, também, a uma ideia de independência. Corresponde a uma "consciência da particularidade infantil, essa particularidade que distingue, essencialmente, a criança do adulto mesmo jovem" (ARIÈS, 1981, p. 134). Trata-se, portanto, de uma sensibilidade em relação à infância, presente nas obras de arte através de imagens de infância, nos chamados objetos especificamente infantis, como o brinquedo, e ainda nas atividades próprias das crianças, como as brincadeiras. Expressa por uma visão otimista da história da infância, essa sensibilidade, porém, está condicionada a um sentimento de infância enquanto configuração coletiva, como produção histórica.

Ariès revelou em seus estudos que a partir do século XIV uma tendência procurou se exprimir na arte, na iconografia, na devoção (no culto aos mortos); e essa tendência demonstrou uma personalidade que se reconhece como criança e que o senso poético e 
familiar atribuiu como sua particularidade. O resultado foi dar à infância, ao menos nas camadas superiores da sociedade nas quais este sentimento aflorou e pode ser documentado, um costume especial que a destacou do mundo dos adultos.

A imagem de infância que conhecemos da Idade Média até os séculos X e XI nos coloca diante de um mundo de representação em que a infância, como conhecemos hoje, é pouco conhecida. Porém, imagens de 1338, no Romanzo di Alessandro, de Johan de Grise, nos mostram crianças/meninas brincando com piões e atestam a presença já de um sentimento que, indiscutivelmente, só se tornou cultura de infância no Renascimento, no interior de um amplo movimento cultural e científico que abriria as portas do mundo moderno. É um tempo de transição, uma rápida passagem, de que se perde a lembrança, mas não o reconhecimento. Já em torno do século XIII, Ariès atestou a presença de tipos de infância que estão mais próximos do sentimento moderno: são os anjos adolescentes, Jesus Menino e a criança nua. Ainda como alegorias da morte e da alma, gestaram outro sentimento em relação à infância, ampliado a partir do século XIV.

Há uma diferença tênue, porém passível de ser isolada no século XIII e que não existia no século $\mathrm{XI}$, de um sentimento de infância na consciência coletiva, observada basicamente na iconografia religiosa: são traços de um realismo sentimental que ultrapassam os limites do religioso e se instalam nas cenas de gênero, transformando-o num cenário cada vez mais profano:

A imagem de uma cena de vida do cotidiano, através de gestos e brincadeiras que pertencem ao mundo infantil, evocadas por um Jesus que expressa uma atitude infantil como jogar os jogos conhecidos de infância com um passarinho amarrado, com uma fruta; a criança come sua papinha ou a criança enfaixada" (ARIÈS, ob. cit., p. 27).

Essa passagem de cenas estritamente religiosas para cenas da vida cotidiana, identificadas na iconografia dos séculos XIV e XV, apresenta, mesmo na iconografia laica, uma representação da infância sempre acompanhada do adulto. É que essas cenas de gênero, identificadas com a vida cotidiana, se desenvolvem transformando a iconografia alegórica convencional, inspirada na concepção antigo-medieval de natureza: idades da vida, estações do ano, sentido, elementos. 
A criança torna-se personagem mais frequente nas pequenas histórias sem, contudo, ser ainda consagrada a uma descrição exclusiva, mas contando entre seus protagonistas, principais ou secundários.

Esse momento sugere a Ariès duas ideias: uma, em que as crianças estão na vida cotidiana misturadas aos adultos, e a outra, em que há uma tendência em particularizar a representação da infância pela sua graça e por seu caráter pitoresco. Identifica, pois, esse sentimento que se destaca pela ingenuidade, gentileza e brincadeiras, como fonte de divertimento e "válvula de escape" para o adulto (mignotage), e um outro que aparece como uma reação crítica a ele, também nos fins do século XV e sobretudo no século XVI, como um sentimento de exasperação, diferente daquele da promiscuidade das idades da sociedade medieval. Nesse sentimento, o que se explicita é a necessidade de separação das crianças do mundo adulto: confirmado no meio dos moralistas e dos educadores do século XVII, ele ultrapassa os limites da particularidade infantil que é o interesse pelo divertimento, a "afadeza", e introduz o interesse psicológico e a preocupação moral. No século XVIII, novos interesses são a esse sentimento associados, vindos também do meio externo e passando a agir na vida familiar: os cuidados de higiene e a preocupação com a saúde psíquica (ARIÈS) ob. cit., p.140-1). São algumas dessas ideias que dão origem à consciência de nossos antepassados para com a infância.

Foi considerando esse universo teórico e investigando não só em muitas outras pesquisas, mas conhecendo in loco na Itália, durante período de estágio de doutorado, que pudemos identificar na iconografia da arte do Renascimento Italiano a presença da imagem do putto como um sentimento que testemunha um grande movimento de interesse em favor da infância, que aparece já no final do século XIV, através do reencontro com o Eros helenístico, e que permanece circulando por interiores e ruas por meio de diferentes formas ainda no século XXI.

O putto designa menino alado e nu, que aparece na

Arte Antiga, personificando várias espécies de espíritos (tais como o espírito do amor e nesse caso chamam-lhe Cupido) geralmente de maneira alegre e brincalhão. Essas imagens foram reintroduzidas na arte no Proto-Renascimento, com seu caráter original ou na qualidade de anjos-meninos (JANSON, 1992, p. 428). 
Cabem aqui duas considerações de rigor na História da Arte: para caracterizar imagem de infância, estamos considerando o termo no seu sentido amplo, isto é, a criança representada na iconografia do Renascimento Italiano; e estamos aceitando a indicação de H. W. Janson para designar Proto-Renascimento como a revolução florentina que abarca tanto a escultura e a arquitetura como a pintura.

Foi necessário circunscrever um plano de estudo que percorresse labirintos, no interior de um entendimento de história de infância como "estudo orgânico das condições de vida, das identidades sociais e dos modelos culturais sucedendo-se no tempo e nas diversas sociedades" (CAMBI, 1991, p. 33). E, mais ainda, caracterizar conceitos referentes à historiografia, ao específico desta a partir da imagem infantil e, por fim, ao conceito mesmo de infância que se inscreve numa história.

Comecemos pela caracterização da historiografia: se aceitamos o entendimento de que se trata de uma "arte de escrever a história", como quer Aurélio Buarque de Holanda Ferreira no Novo Dicionário da Língua Português (e insiste na citação de Fidelino de Figueiredo, em “Entre Dois Universos”, pág. 209: “A filosofia da história partirá de fronteiras últimas da historiografia para especular livremente sobre problemas e inquietações que não cabem nos domínios da história científica”), diríamos que existe um espaço que uma certa licença poética poderá preencher. No interior deste espaço - de fronteiras - cabe, perfeitamente, o estudo acerca de imagens infantis. Estas, por sua vez, como segunda explicação, têm caráter próprio, ao se apresentarem como materialidade da infância.

Retornando ao ponto de partida, o movimento indica que as imagens infantis que compõem uma historiografia da infância inserem-se, na sua especificidade, numa história da infância. Explicitemos essas questões no âmbito da pesquisa científica.

Uma história da infância, com as características da iniciada na década de 60 na França, com Philippe Ariès, foi decisiva para a "individualização da especificidade e dos valores desta área de pesquisa histórica” (Idem). Ligada à "história das mentalidades, à metodologia dos Anais e ao estudo de novos objetos históricos", essa perspectiva absorveu objetos tradicionalmente ignorados e em diferentes âmbitos, como 
marginalidade, os sentimentos, o imaginário, etc. Citemos as três diferentes perspectivas de pesquisa histórica a que a história da infância está filiada: além da representada por Ariès, a história social ligada a Stone e não muito distante da historiografia dos Anais, mas atenta aos acontecimentos mais descritivos (e menos "estrutural”), que sonda todos os aspectos de uma sociedade e recupera a sua particular especificidade, como também em De Mause - História da Infância - e aquela do freudmarxismo e do estruturalismo, sobretudo o francês, que relançou no "mercado de ideias" o princípio da alteridade da infância e o da sua manipulação social, como em Foucault - Vigiar e Punir -, Vigarello e, em parte, Geremek (cf. CAMBI, 1990, p. 33-48).

É importante recorrermos a um embasamento teórico confiável, em torno de estudiosos que levantaram a problemática de uma historiografia da infância. Na Itália, Egle Becchi como pesquisadora contribuiu significativamente para os estudos sobre a infância, que concentraram conceituados profissionais em torno da temática. Em “Metáforas da Infância”, escrevendo sobre Retórica da Infância, ela reforça a necessidade de ultrapassar os limites do adulto que fala pela criança e de recuperar, ao menos tendencialmente, a realidade infantil, pondo, para além da pedagogia e da ideologia, a materialidade mesma da infância, dando espaço a desejos, gestos, palavras que falam, de alguma maneira, da criança (Idem, p. 36).

Em "Por uma História da Infância como Figura Educativa”, comenta a pobreza de arquivo histórico e a ausência de uma história da criança durante muitos séculos e milênios, apontando a necessidade de uma arqueologia, mas de uma arqueologia em que os depósitos do imaginário se multipliquem, mesmo com o risco de superestimar indícios e testemunhos episódicos (BECCHI, 1987, p. 183).

Debruçando-se sobre Walter Benjamin (o gesto e o signo), Deligny (o movimento e o caminho), Deligny, Mannoni e Seligmann (o silêncio e o sintoma) ${ }^{1}$ Becchi sinaliza a

${ }^{1} \mathrm{O}$ artigo "Retórica de Infância”, originalmente publicado na Revista aut aut, Milano: 191-192, setembrodezembro, 1982: 3-26, em Metafore d'Infanzia; no Brasil, foi editado pela EDUFSC, Florianópolis/SC, Tradução de Ana Gomes. “A Modernidade, a Infância e o Brincar”. In: Revista Perspectiva, n. 2, 1994.

Na obra citada, Cambi também faz um excelente mapeamento das oposições de paradigmas entre Ariès, De Mause e Postman. A diferença, basicamente, está no sentimento de infância de Ariès - uma visão otimista 
possibilidade de interpenetrar a via longa e sofisticada (com) uma outra possibilidade teoricamente menos refinada, de dar palavra à infância, aquela que aproxima para além da figura de retórica, visando a falar e consentindo resposta, permitindo-lhe comunicações outras que a palavra, como o gesto e o sinal, o movimento e o caminho, o silêncio e o sintoma e dando espaço e direito a tais linguagens (BECCHI, 1982, p. 24-5).

Dos paradigmas utilizados para elaborar uma história da infância, os traçados por Ariès têm merecido destaque na comunidade científica: compondo um quadro de aspectos históricos considerados de "longa duração", são os elementos que se ligam à descoberta/valorização da infância, promovidos numa longa, mas progressiva transformação social que se coloca no cruzamento de uma expansão da família nuclear, de uma cultura de sentimentos e de uma orgânica planificação da sociedade, realizada no âmbito da modernidade (CAMBI, 1990, p. 39) ${ }^{2}$. As categorias-chave que ele utiliza, descoberta e sentimento de infância e, também, binômio cuidado/controle e privatização - familiarização da criança, formam um núcleo de paradigmas que desenvolveu uma história da infância.

Seguindo os passos de Ariès, Becchi uniu os paradigmas-fontes (descoberta e valorização da infância) aos estruturalistas e freudmarxistas franceses e trabalhou com a privatização - familiarização da infância numa perspectiva histórico-ideológica; Ana Maria Bernardino, ao pesquisar a infância na Pádua do Oitocentos, numa perspectiva históricosocial, concentrou-se no binômio cuidado/controle, mais no aspecto do controle, da conformidade, do predomínio da ideologia, como aspecto dominante na moderna história da infância; e Leonardo Trisciuzzi desenvolveu o aspecto do conhecimento científico da infância, demonstrando que a descoberta da criança não é só uma descoberta social mas, na modernidade, está aliada ao nascimento das ciências humanas,

\footnotetext{
da infância -, contraposto ao paradigma de De Mause - continuidade e centralização da violência exercida sobre a criança e a consciência da atenção e respeito à infância, em modelos menos uniformes, convergindo para a relação pais e filhos, que vão do "infanticídio" ao "cuidado". Em Postman, a nova imagem da infância na modernidade está pontuada pela "idade da imprensa" e, principalmente, pela "idade da televisão", cancelando a separação da infância e aproximando-a da idade adulta, submetendo-a às mesmas experiências do imaginário. $O$ "desaparecimento da infância” encerra uma longa idade histórica e desenvolve o "adultismo", num retrocesso ao mundo tradicional, agora com a perversidade da dependência tecnológica, que vai do isolamento da criança à passividade psicológica. Ver p. 37-40.

${ }^{2}$ Erwin Panofski. Significado nas Artes Visuais. São Paulo: Ed. Perspectiva, 1974, principalmente p. $33-87$.
} 
envolvendo o imaginário científico e contribuindo para o avanço dessa perspectiva de história de infância.

Essa história se constituiu cruzando diferentes campos do conhecimento, como o historiográfico, o filosófico, o histórico-epocal, também historiadores puros e antropólogos culturais, psicólogos, sociólogos e, principalmente, pedagogos e historiadores da infância.

Para Cambi, esses estudos, ao gerar um rápido crescimento de pesquisas que articularam diferentes áreas culturais, atingiram um estágio problemático e atravessado de exigências de rigor científico.

Sumariamente, podemos apontar um importante estágio de desenvolvimento das pesquisas em três orientações, que assumem formas bastante orgânicas: a da história social da infância, a das imagens da infância e a do imaginário da infância. O desenvolvimento das orientações é bastante desigual e com encaminhamentos metodológicos diferentes. Estão caracterizadas como três níveis da realidade infantil: vida social, imagens sociais e culturais, vida do imaginário.

A pretensão aqui é se aproximar à orientação sobre imagens sociais e culturais da infância, desenvolvendo características próprias. No contexto geral, porém, admite-se buscar demarcações e reconstruções de imagens que, numa evolução história, filtram ideologias que reveem a infância.

Cabe um esclarecimento sobre a especificidade das imagens a que nos referimos. Mesmo que se admita a periodização estabelecida pelos estudiosos da história da infância - uma distinção entre o mundo tradicional clássico e medieval e o mundo burguês e que nos apresenta duas diferentes imagens de infância - temos, de imediato, dois problemas: um, referente à existência de um espaço que estava até então vazio, mas significativo na iconografia sobre a infância, que foi o período do Renascimento, época em que a infância realmente apareceu como construção social/coletiva, e o outro, uma percepção parcelada, quase de ruptura de uma possível articulação entre o mundo tradicional e o mundo moderno, verificado no objeto de estudo (imagens de infância na arte), que, apesar de fragmentário, traça um fio nada invisível. 
Assim, o sentimento de infância, enquanto configuração coletiva da imagem da criança, presente na obra de Donatello, Mantegna e Tiziano e que se configura como "a meio caminho entre o sagrado e o profano", é indicador de um espaço social em que o tempo mostra não mais a criança como um homem ou uma mulher em miniatura, de tamanho reduzido, mas com natureza própria, integrada a espaços vitais proporcionais.

O surgimento dessa concepção de infância é anterior à que temos na sociedade contemporânea, visto que surgiu no final do século XVIII com a industrialização, porém permanece entre nós em decorrência da manutenção do tipo de sociedade em que vivemos: uma dualidade em que a infância é dividida entre a criança burguesa, privatizada pela família, e a criança que trabalha explorada, ou melhor, entre as crianças protegidas e aquelas entregues à própria falta de sorte. Enfim, a dualidade permanece.

Poderíamos estudar a infância analisando "materiais" que partem do presente ou do passado. Uma investigação prática não deixaria de optar, provavelmente, pela constatação do significado de infância existente. Mas a resposta à questão (por que motivos devemos empenhar-nos em investigações não-práticas e interessar-nos pelo passado?) prende-se à condição de que é porque nos interessamos pela realidade. E para apreendermos a realidade temos que nos distanciar do presente.

Com Panofski, ${ }^{3}$ aprendemos que, para analisar as ações e criações humanas, precisamos empenhar-nos em um processo mental de caráter sintético e subjetivo; tal procedimento nos levará a refazer as ações e recriar mentalmente as criações. Nessa tarefa, denominada investigação humanista, podemos nos utilizar de dois momentos organicamente incorporados: a recriação estética intuitiva e a pesquisa arqueológica interligadas, formando uma situação orgânica. Ao submeter o seu "material" a uma análise arqueológica racional, um “material” constituído por uma recriação estética intuitiva (incluindo a apreciação de “qualidade”), o pesquisador estará agindo do mesmo modo que uma pessoa "comum” faz quando vê um quadro ou escuta uma sinfonia.

O esforço concentrado na iconografia enquanto "arte de representar por meio de imagem" e de utilizar recursos além da palavra escrita ao basear-nos em linguagens

\footnotetext{
${ }^{3}$ Ferreira Goulart, no ensaio “A aura e a obra”. In: Revista Continente, dez. 2004.
} 
visuais que reelaboram conceitos e informações (gesto possibilitado por uma certa licença poética que a arte permite, como a seleção do detalhe, a montagem de imagens através da recriação artística) não garante uma historiografia acabada da infância, porém registra um ponto relevante: as imagens de infância possuem a aura que a modernidade insistiu e insiste em acabar, constantemente ameaçada quando se espelha na contemporaneidade. Sobrevive. Tal qual o "princípio-esperança" que talvez possa construir uma "aura" totalmente nova, a vontade de encantamento e reencantamento do mundo, movimento teimoso que explode sempre em algum canto, lhe garante um lugar na história.

Ferreira Goulart ${ }^{4}$ enfatiza que a "aura", ao invés de acabar na modernidade, como afirmava Walter Benjamin, aumentou nos nossos tempos: porque parece que "envolver os objetos em aura é uma necessidade do ser humano", o que também nos permite admitir que as imagens de infância, através dos tempos, independente dos diferentes tipos de organização social, permanecem e podem ser instrumentos de preservação e garantias para ações igualitárias e contundentes no desenvolvimento da humanidade.

\section{Referências}

AGAMBEN, Giorgio. Infância e História. Belo Horizonte: UFMG, 2008.

ARIÈS, Philippe e MARGOLIN, Jean-Claude. Les Jeux à la Renaissance. Paris: Librairie Philosophique J. Vrin, 1982.

. História Social da Criança e da Família. 2. ed. Rio de Janeiro: Guanabara, 1981.

BAKHTIN, Mikhail. A cultura popular na Idade Média e no Renascimento. O contexto de François Rabelais. São Paulo: HUCITEC; Brasília: Editora da Universidade de Brasília, 1987.

BAXANDALL, Michael. O Olhar Renascente. Pintura e Experiência Social na Itália da Renascença. Rio de Janeiro: Paz e Terra, 1991.

\footnotetext{
${ }^{4}$ A revisão deste artigo foi feita por Maria Tereza de Queiroz Piacentini, autora dos livros "Não Tropece na Língua: lições e curiosidades do português brasileiro" (Ed. Bonijuris, 2012) e "Só Vírgula: método fácil em vinte lições" (Ed. da Ufscar, 2009), entre outros.
} 
BENJAMIN, Walter. Angelus novus, saggi e frammenti. Torino: Giulio Einaudi Edit., 1962. . “Magia e Técnica, arte e política”. In: Obras Escolhidas, v. I, São Paulo: Brasiliense, 1987. . A modernidade e os modernos. Rio de Janeiro: Tempo Brasileiro, 1975. . Reflexões: a criança, o brinquedo, a educação. São Paulo: Summus, 1984. . Documentos de Cultura, Documentos de Barbárie. São Paulo: Cultrix/Editora da USP, 1986.

BROUGÈRE, Gille. Brinquedo e Cultura. São Paulo: Cortez, 1995.

DE MAUSE, L. Storia dell'Infanzia. Milano: Emme Edizione, 1983.

ERIKSON, Eric H. Il gioco del bambino e le ragione dell'adulto. Roma: Armando Armando, 1981.

GAGNEBIN, Jeanne Marie. Os cacos da História. São Paulo: Brasiliense, 1982. . História e Narração em Walter Benjamin. São Paulo: Perspectiva, Campinas: Editora da Universidade Estadual de Campinas, 1994.

GOMBRICH, E. H. A História da Arte. 4. ed. Rio de Janeiro: Guanabara, 1988.

JANSON, H. W. História da Arte. 5. ed. São Paulo: Martins Fontes, 1992.

PANOFSKY, Erwin. Significado nas Artes Visuais. São Paulo: Perspectiva,1979.

\section{Artigos}

BECCHI, Egle. A Modernidade, a Infância e o Brincar. In: Telma Anita Piacentini (Org.). Traduzido por Ana Gomes. Revista Perspectiva, Florianópolis/UFSC, n. 22, ago./dez. 1994. p. 63-95. Tradução do italiano: Metafore d'Infanzia. Rivista aut aut, Milano: Nuova Serie, 191-2, settembre-dicembre, 1982, p. 3-26. “Retorica d'Infanzia”.

BENJAMIN, Walter. "Programma di un teatro proletario dei bambini (1928)". Trad. de Elvio Facchinelli, em Quaderni Piacentini, n. 38, 1069. In: A Lacis, Professione:

Revoluzionaria. Milano: Feltrinelli, 1976. p. 83-89. 
BERNARDINIS, Anna Maria. “Appunti per una storiografia pedagogica dell'infanzia”. In: Storiografia dell'Infanzia. Ferrara: Biblioteca del Bolletino, Saggi 1, Cirse, 1990. p. 9-13.

BERTOLINI, P. e CALLARI GALLI, M. “I fili contorni dell'infanzia'. In: Per amore \& Per Forza. L’Infanzia tra'800 e ‘900. Modena: Edizione Panini, s/d.

BOLLI, Willi. “A modernidade segundo Walter Benjamin”. In: Revista da Universidade de São Paulo. São Paulo, (5) jun. 1987. p. 45-56.

BROUGÈRE, Gille e MANSON, Michel. "Images et fonctions sociales du jouet anthropomorphe." In: Études et Documents - n. 2. Departement des Sciences du Jeu. Université Paris - Nord, 1989-90. p. 66-82.

CAMBI, Franco. “La Storia dell'Infanzia - Questioni di Metodo”. In: Storiografia dell'Infanzia. Ferrara: Biblioteca del Bollettino, Saggi 1, Cirse, 1990. p. 33-48.

FERREIRA GULLAR. “A aura e a obra”. In: Revista Continente. Recife, $1^{\circ}$ dez. 2004.

PANCERA, Carlo. A Modernidade, a Infância e o Brincar. In: Telma Anita Piacentini (Org.). Traduzido por Maria Teresa Arrigoni. Revista Perspectiva, n. 22, ago./dez. 1994. p. 97-104. Tradução do italiano: "Semantiche d'Infanzia". In: Metafore d'Infanzia. Rivista aut aut. Milano: Nuova Serie, 191-2, settembre-dicembre, p.191-196.

PIACENTINI, Telma Anita. "Imagens de Infância na arte italiana”. In: Silvana de Gaspari (Org.). Revista Fragmentos, n. 33, Florianópolis: UFSC, 2007. p. 371-380.

. "A questão do método e a pesquisa sobre imagens de infância”. In: Monica Fantin e Gilka Girardello (Orgs.). Liga, Roda, Clica. Campinas: Papirus, 2008. p.57-74.

SARACENO, Chiara. “La socializzazione infantile come definizione dell'infanzia”. In: II Bambino Sociale. BECCHI, Egle (Org.). Milano: Feltrinelli, 1978. p. 114-149.

\section{Jornal}

ARGAN, Giulio Carlo. L'Arte Italiana del Rinascimento al Neoclassico. Editorial Quotidiani - RCS. Sansoni Editori. Supplemento al Corriere della Sera, 17 settembre 1991. 
Recebido em: 20/11/2012 Aprovado em: 05/06/2013

Universidade do Estado de Santa Catarina - UDESC Programa de Pós-Graduação em Educação - PPGE Revista Linhas Volume 14 - Número 26 - Ano 2013 revistalinhas@gmail.com 